\title{
SARS-CoV-2/COVID-19: el virus, la enfermedad y la pandemia
}

\section{SARS-CoV-2/COVID-19: The virus, the disease and the pandemic}

\author{
Francisco Javier Díaz-Castrillón ${ }^{1}$, Ana Isabel Toro-Montoya²
}

\begin{abstract}
Resumen. El brote de la enfermedad por coronavirus 2019 (COVID-19), causado por el virus del síndrome respiratorio agudo severo tipo-2 (SARS-CoV-2), fue declarado como una pandemia en marzo de 2020. Las tasas de letalidad se estiman entre $1 \%$ y $3 \%$, afectando principalmente a los adultos mayores y a aquellos con comorbilidades, como hipertensión, diabetes, enfermedad cardiovasculary cáncer. El periodo de incubación promedio es de 5 días, pero puede ser hasta de 14 días. Muchos pacientes infectados son asintomáticos; sin embargo, debido a que liberan grandes cantidades de virus, son un desafío permanente para contener la propagación de la infección, causando el colapso de los sistemas de salud en las áreas más afectadas. La vigilancia intensa es vital para controlar la mayor propagación del virus, y el aislamiento sigue siendo el medio más efectivo para bloquear la transmisión. Este artículo tiene como objetivo revisar el virus causante de esta nueva pandemia COVID-19 que afecta al mundo, mayor aún que la de influenza A H1N1 en 2009, la cual significó la muerte de cientos de miles de personas en todo el mundo. Se abordan temas como el patógeno, la epidemiología, las manifestaciones clínicas, el diagnóstico y el tratamiento.
\end{abstract}

Palabras clave: COVID-19, coronavirus, SARS-CoV-2, epidemiología, diagnóstico, manifestaciones clínicas, tratamiento.

Abstract. The outbreak of coronavirus disease 2019 (COVID 19), caused by the severe acute respiratory syndrome coronavirus 2 (SARS-CoV-2), was declared a pandemic in March 2020. Fatality rates are estimated to be between 1\% and 3\%, affecting primarily the aging population and those with comorbidities, such as hypertension, diabetes, cardiovascular disease and cancer. The average incubation

\footnotetext{
${ }^{1}$ Médico, Especialista en Microbiología y Parasitología Médicas, PhD en Virología. Profesor, Facultad de Medicina, Sede de Investigación Universitaria (SIU), Universidad de Antioquia. Medellín, Colombia.

${ }^{2}$ Bacterióloga y Laboratorista Clínica. MSc en Virología. Directora Científica, Editora Médica Colombiana S.A. Medellín,

Colombia. E-mail: atoro@edimeco.com

Conflicto de interés: los autores declaran que no tienen conflicto de interés.

Medicina \& Laboratorio 2020;24:183-205. https://doi.org/10.36384/01232576.268

Recibido el 24 de abril de 2020; aceptado el 26 de abril de 2020. Editora Médica Colombiana S.A., $2020^{\circ}$.
} 
period is 5 days but can be as long as 14 days. The majority of infected patients are asymptomatic; however, they release large amounts of viral particles that contribute to the challenges for containing the spread of the infection, and threatening to overwhelm health systems. Intense surveillance is vital for controlling the further spread of the virus, and isolation remains the most effective means of blocking the spread of the disease. This article aims to review the virus and the disease involved in a new pandemic since the appearance of H1N1 flu in 2009, which killed hundreds of thousands worldwide. Topics such as the pathogen, epidemiology, clinical features, diagnosis and treatment will be covered.

Keywords: COVID-19, coronavirus, SARS-CoV-2, epidemiology, diagnosis, clinical manifestations, treatment.

\section{Introducción}

En el mes de diciembre de 2019, un brote de casos de una neumonía grave se inició en la ciudad de Wuhan, provincia de Hubei, en China. Los estudios epidemiológicos iniciales mostraron que la enfermedad se expandía rápidamente, que se comportaba más agresivamente en adultos entre los 30 y 79 años, con una letalidad global del 2,3\% [1]. La mayoría de los primeros casos correspondían a personas que trabajaban o frecuentaban el Huanan Seafood Wholesale Market, un mercado de comidas de mar, el cual también distribuía otros tipos de carne, incluyendo la de animales silvestres, tradicionalmente consumidos por la población local $[2,3]$.

Los estudios etiológicos iniciales dirigidos a los agentes comunes de la infección respiratoria aguda, incluyendo los agentes de la influenza aviar, del síndrome respiratorio agudo severo (SARS, del inglés, Severe Acute Respiratory Syndrome) y del síndrome respiratorio del Medio Oriente (MERS, del inglés, Middle East Respiratory Syndrome), arrojaron resultados negativos. El uso de métodos de secuenciación profunda, que no requieren información previa sobre el agente que se busca, así como el aislamiento en cultivo de células, seguido de microscopía electrónica y de secuenciación profunda, demostró que se trataba de un agente viral nuevo, perteneciente al grupo de los coronavirus, y fue inicialmente llamado 2019-nCoV (novel coronavirus de 2019), genéticamente relacionado, pero distinto al agente del SARS [1,3,4].

El brote se extendió rápidamente en número de casos y en diferentes regiones de China durante los meses de enero y febrero de 2020. La enfermedad, ahora conocida como COVID-19 (del inglés, Coronavirus disease-2019), continuó propagándose a otros países asiáticos y luego a otros continentes [1,3]. El 11 de marzo de 2020, la Organización Mundial de la Salud (OMS) declaró la ocurrencia de la pandemia de COVID-19, exhortando a todos los países a tomar medidas y aunar esfuerzos de control en lo que parece ser la mayor emergencia en la salud pública mundial de los tiempos modernos [5].

\section{Agente etiológico}

El virus del síndrome respiratorio agudo severo tipo-2 (SARS-CoV-2), causante de COVID-19, se ubica taxonómicamente en la familia Coronaviridae 
[6]. Esta familia se subdivide en cuatro géneros: Alphacoronavirus, Betacoronavirus, Gammacoronavirus y Deltacoronavirus $[7,8]$. Muchos coronavirus de los cuatro géneros mencionados son causantes de enfermedades en animales domésticos, y por lo tanto son principalmente de interés veterinario [9]. Los coronavirus de importancia médica conocidos hasta hoy son siete, y pertenecen a uno de los dos primeros géneros mencionados [7]. Desde el punto de vista ecoepidemiológico se pueden clasificar en dos grupos: coronavirus adquiridos en la comunidad (o coronavirus humanos, $\mathrm{HCoV}$ ) y coronavirus zoonóticos (tabla 1).

Los coronavirus humanos circulan libremente en la población de todos los continentes, suelen causar enfermedad respiratoria leve. Se estima que producen entre el $10 \%$ y el $30 \%$ de los casos de resfriado común $[7,10]$. Por el contrario, los coronavirus zoonóticos circulan transitoriamente, pero pueden generar grandes epidemias de enfermedad respiratoria grave [9].

El origen de los coronavirus de importancia médica, incluidos los coronavirus humanos, parece ser zoonótico. En particular, los betacoronavirus zoonóticos están filogenéticamente relaciona- dos con coronavirus de murciélagos, los cuales podrían haber sido su fuente para el hombre, ya sea directamente o a través de un hospedero intermediario; dicho intermediario para el SARSCoV fue la civeta, un animal silvestre del grupo de los vivérridos, y para el MERS-CoV fue el dromedario $[4,7,8]$. Aún no es claro cuál pudo haber sido el intermediario para el SARS-CoV-2, o si pasó directamente del murciélago al humano. En la figura 1 se observa un árbol filogenético que muestra las relaciones evolutivas de los coronavirus de importancia en salud humana, y algunos de sus parientes más cercanos.

\section{Estructura viral}

Los coronavirus tienen forma esférica o irregular, con un diámetro aproximado de $125 \mathrm{~nm}$. Su genoma está constituido por RNA de cadena sencilla, con polaridad positiva, y con una longitud aproximada de 30.000 ribonucleótidos [11]. Poseen una cápside de simetría helicoidal, constituida por la proteína de nucleocápside (N). La proteína $\mathrm{N}$ es la única presente en la nucleocápside y se une al genoma viral en forma de rosario; se cree que participa en la replicación del material genético viral en la célula y en el empaquetamiento del

Tabla 1. Clasificación de los coronavirus de importancia en la salud humana

\begin{tabular}{l}
\hline Adquiridos en la comunidad (asociados con enfermedad respiratoria leve) \\
\hline HCoV $229 E$ \\
HCOV OC43 \\
HCoV NL63 \\
HCoV HKU-1 \\
\hline Zoonóticos (asociados con enfermedad respiratoria grave) \\
\hline SARS-CoV. Coronavirus del síndrome respiratorio agudo severo (SARS) \\
MERS-CoV. Coronavirus del síndrome respiratorio del Medio Oriente (MERS) \\
SARS-CoV-2. Coronavirus de COVID-19
\end{tabular}

CoV: coronavirus; HCoV: coronavirus humano. 


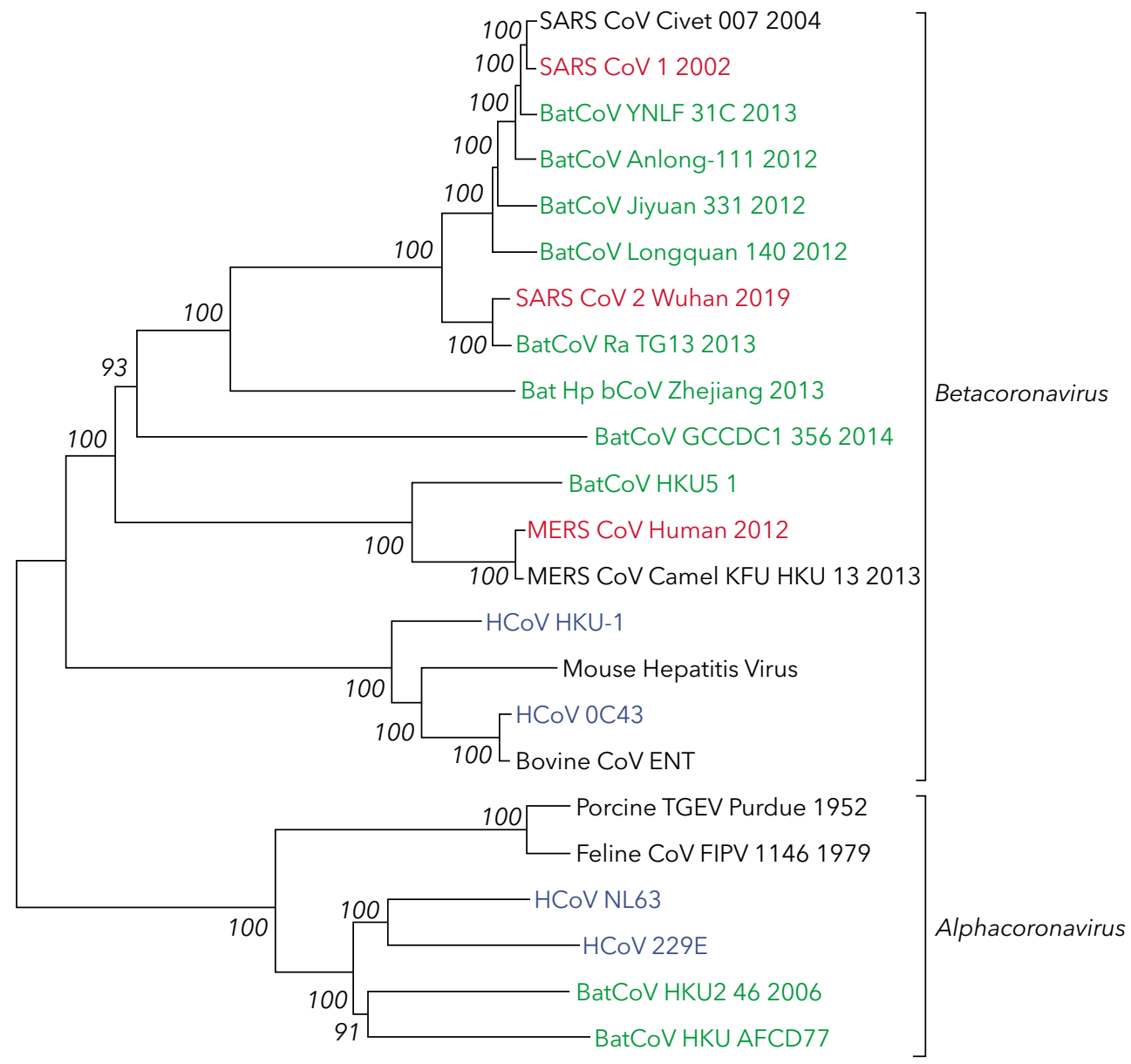

Figura 1. Árbol filogenético de los coronavirus de importancia médica y otros coronavirus animales. Los coronavirus humanos ( $\mathrm{HCoV}$ ) adquiridos en la comunidad se muestran en azul, los coronavirus zoonóticos en rojo, los encontrados en murciélagos en verde, y otros coronavirus de animales en negro. Los números cerca a los nodos del árbol corresponden al soporte estadístico o valor de "bootstrap".

mismo en las partículas virales [11]. Los coronavirus tienen una envoltura lipídica con tres proteínas ancladas en ella, denominadas $E$ (envoltura), M (membrana) y $\mathrm{S}$ (del inglés, spike, o espícula), la cual le da al virión (partícula infecciosa) la apariencia de una corona [11,12], y es la proteína que media la unión al receptor y facilita su fusión con la membrana celular [4] (figura 2). Las funciones de las proteínas $\mathrm{M}$ y $\mathrm{E}$ aún no están bien establecidas, pero se considera que podrían participar en el ensamblaje y liberación del virión $[3,11]$.

El genoma viral es notable por su extensión de aproximadamente $30 \mathrm{~kb}$ con 15 marcos de lectura abiertos (ORFs, del inglés, Open Reading Frames) [3,13], que le permiten formar hasta 28 proteínas, un número inusualmente elevado para un virus con geno- 

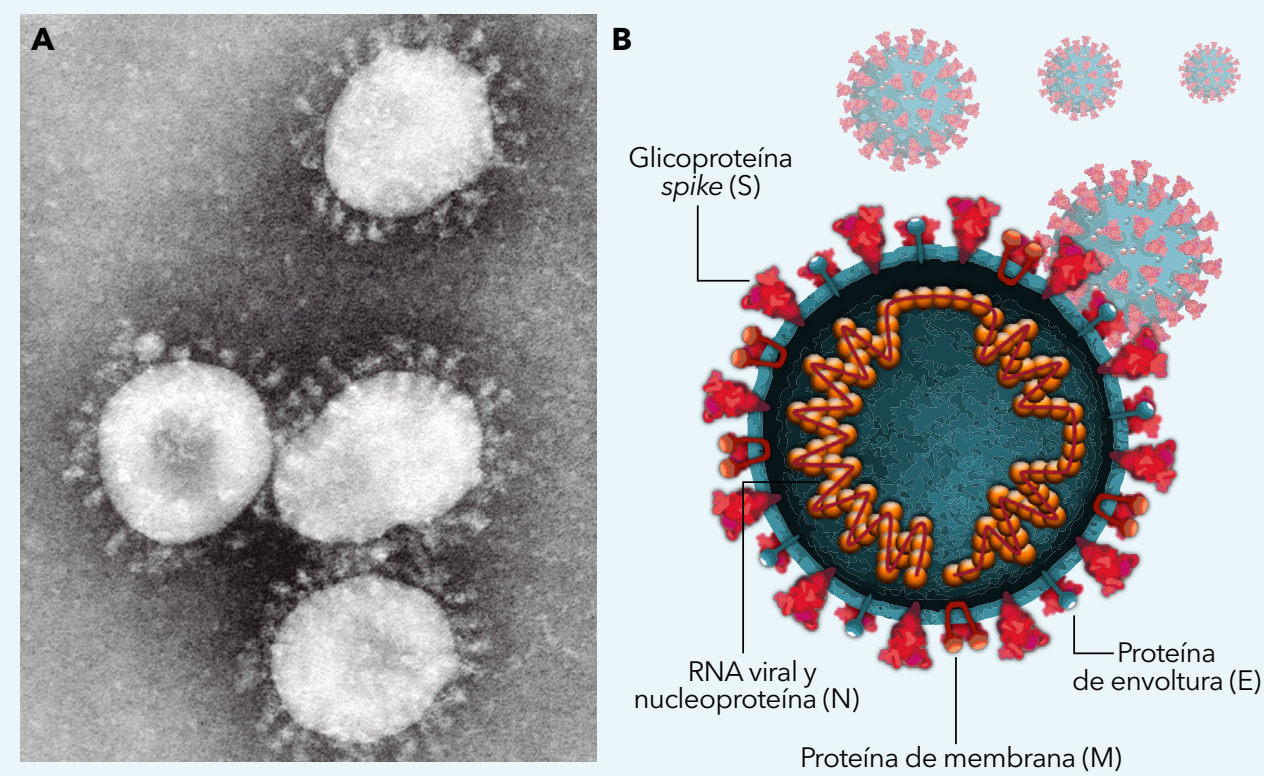

Figura 2. (A) Microfotografía del virión. (B) Esquema de la estructura del SARS-CoV-2, que muestra los diferentes componentes estructurales del virión. Una de las características más destacadas es la presencia de unas proyecciones prominentes o espículas que sobresalen de la superficie viral, y que están formadas por trímeros de la proteína S. Estas espículas están ancladas en una membrana lipídica que constituye la envoltura viral. También en la envoltura hay otras dos proteínas, la M y la E. Al interior de la envoltura está la nucleocápside viral, la cual está conformada por el ácido nucleico viral y por múltiples unidades de la proteína $\mathrm{N}$, organizadas en simetría helicoidal, que protegen el genoma.

ma RNA de cadena sencilla. La mayoría de las proteínas codificadas en dichos ORFs no hacen parte de la estructura del virión, y por lo tanto se denominan no estructurales (NS) [3]. Además, el genoma cuenta con un extremo 5 ' no codificante, el cual tiene un gorro o cap, y un extremo 3' con una cola de poli (A), que le permiten actuar como RNA mensajero (mRNA) [7,11]. Aproximadamente las dos terceras partes codificantes del genoma hacia el extremo 5 ' están ocupadas por los ORFs 1 a y $1 \mathrm{~b}$, los cuales generan poliproteínas largas, que mediante proteólisis producen una gran cantidad de proteínas no estructurales de tamaño variable. Entre estas se destacan la RNA polimerasa dependiente de RNA (RdRp), una helicasa y dos proteasas; estas últimas se encargan de partir las poliproteínas en sus fragmentos funcionales. La otra tercera parte del genoma, hacia el extremo 3', contiene los ORFs correspondientes a las proteínas estructurales ( $\mathrm{S}$, $\mathrm{E}, \mathrm{M}$ y N) y a otras nueve proteínas pequeñas de función desconocida, que se traducen a partir de mRNAs subgenómicos [11] (figura 3 ).

\section{Replicación viral}

Al llegar a la célula blanco, la proteína S se une al receptor en la célula, la enzima convertidora de angiotensina 2 (ACE2). La proteína S es luego clivada por una proteasa celular (TMPRSS2), 


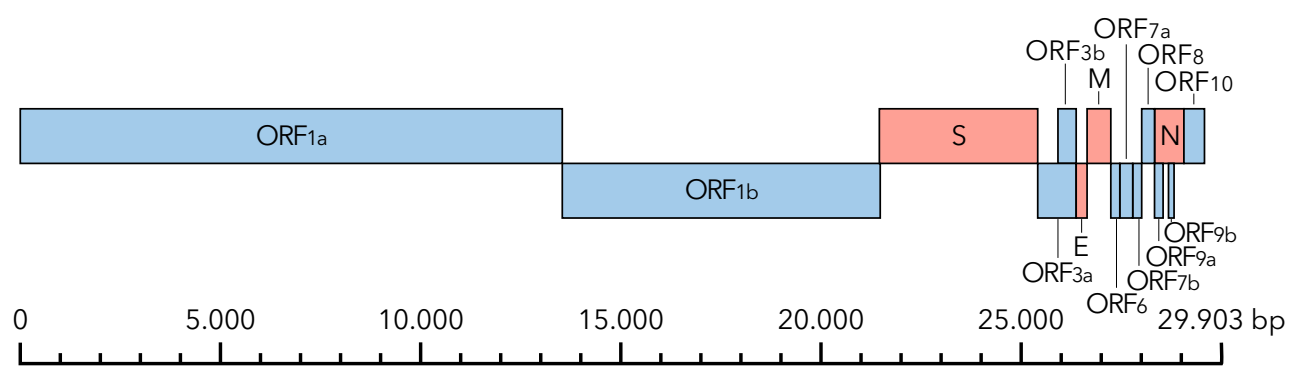

Figura 3. Estructura del genoma del SARS-CoV-2. Dos tercios del RNA viral, ubicados en el extremo 5' (ORF1 a y ORF 1b), generan dos poliproteínas no estructurales: 1 a y $1 \mathrm{ab}$. La parte restante del genoma del virus codifica para otras proteínas de función desconocida y para las cuatro proteínas estructurales: la S (spike), la E (envoltura), la M (membrana) y la N (nucleocápside).

en dos subunidades, S1 y S2. La subunidad $\mathrm{S} 1$ contiene el dominio de unión al receptor $(\mathrm{RBD}$, del inglés, Receptor Binding Domain), en tanto que la subunidad S2 contiene el péptido para la fusión a la membrana celular [3,8]. Luego de su entrada a la célula, mediante la formación de un endosoma, el virus es desenvuelto y el RNA viral es liberado al citoplasma, para iniciarse en los ribosomas la traducción. de los genes ORF $1 \mathrm{a}$ y $1 \mathrm{~b}$ en sus proteínas, las cuales realizan la replicación del genoma viral. Las proteínas estructurales codificadas hacia el extremo 3 ' son traducidas a partir de mRNAs transcritos desde la hebra de polaridad negativa que se forma durante la replicación del genoma viral. Estas proteínas estructurales son posteriormente ensambladas con el genoma viral, en las membranas celulares internas del retículo endoplasmático y aparato de Golgi, formándose las nuevas partículas virales. Finalmente, las vesículas que contienen los nuevos viriones se fusionan con la membrana celular para liberar los virus al exterior de la célula, proceso llamado exocitosis [3,11-13] (figura 4).

\section{Epidemiología}

A la fecha, abril 24 de 2020, se han confirmado más de 2,6 millones de casos de COVID-19 a nivel mundial, con un estimado de 180.000 muertes y más de 700.000 pacientes recuperados, números que cambian día a día, y que pueden ser monitoreados en tiempo real en el sitio web de la Universidad Johns Hopkins [14], o con el Worldometer [15]. En Colombia, en particular, a la misma fecha, se han confirmado 4.881 casos, con 225 muertes y 927 pacientes recuperados, de acuerdo con el Instituto Nacional de Salud [16], siendo la ciudad de Bogotá la más afectada hasta el momento, con 2.065 casos confirmados.

De acuerdo con la OMS, las definiciones de los casos se establecen de la siguiente manera [17]:

\section{Caso sospechoso:}

- Paciente con enfermedad respiratoria aguda (con fiebre y al menos un signo o síntoma de enfermedad respiratoria, como 


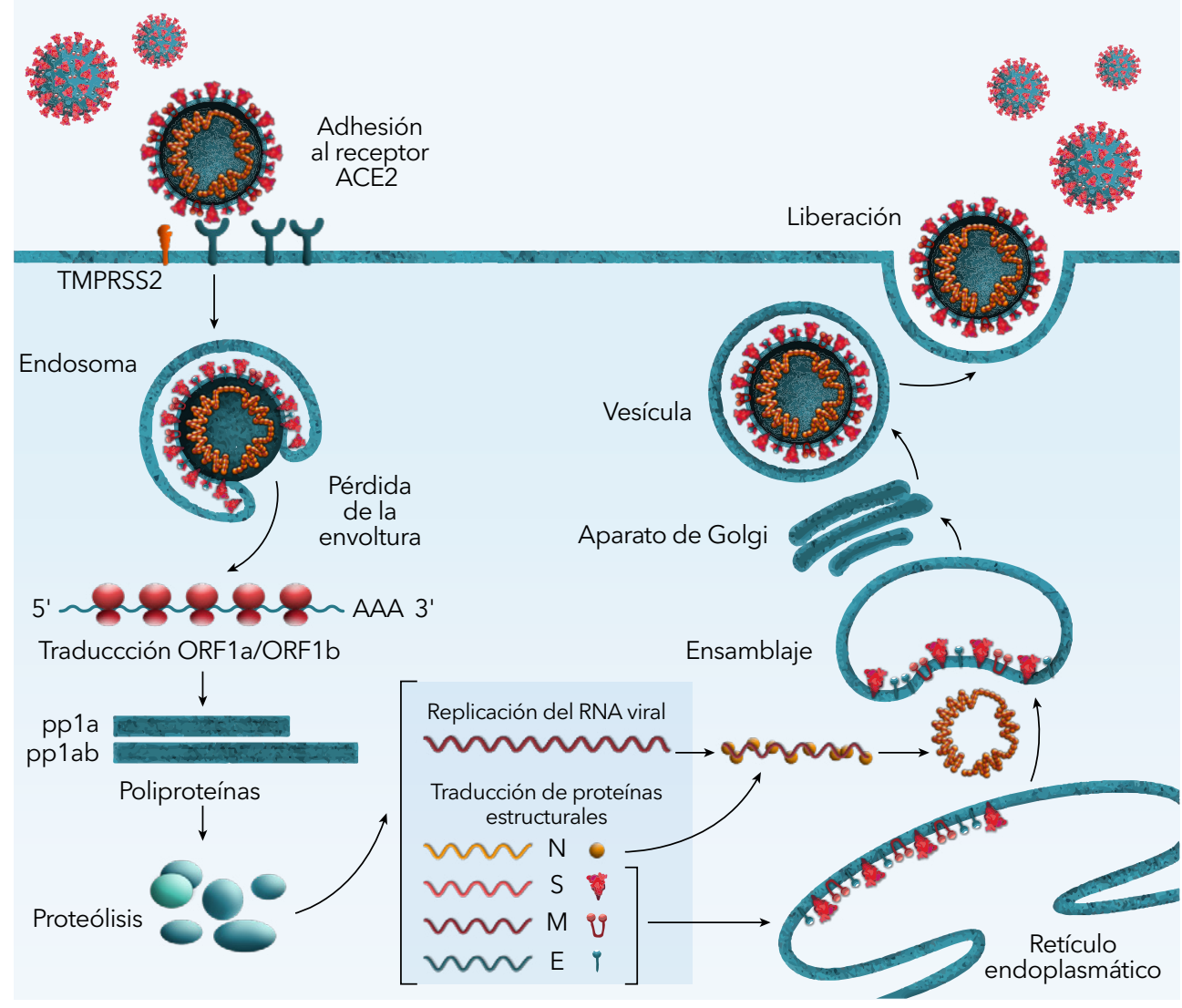

Figura 4. Replicación del SARS-CoV-2.

tos, disnea, etc.), $\mathbf{Y}$ con historia de viaje o de residencia en un área en la que se haya reportado transmisión comunitaria de $\mathrm{CO}$ VID-19, en los 14 días previos a la aparición de los síntomas.

- Paciente con enfermedad respiratoria aguda, $\mathbf{Y}$ que haya estado en contacto con un caso probable o confirmado de COVID-19, en los 14 días previos a la aparición de los síntomas.

- Paciente con enfermedad respiratoria aguda severa (con fiebre y al menos un signo o síntoma de enfermedad respiratoria severa, como tos, disnea, etc.), $\mathbf{Y}$ que requiera hospitalización, $\mathbf{Y}$ que no tenga otra alternativa diagnóstica que pueda justificar la clínica.

\section{Caso probable:}

- Caso sospechoso con resultados no concluyentes en las pruebas para la detección de SARS-CoV-2.

- Caso sospechoso en quien no se haya podido realizar una prueba diagnóstica. 
Caso confirmado: paciente con prueba positiva de laboratorio para SARSCoV-2, sin importar su situación clínica.

Contacto: un contacto es una persona que haya tenido exposición a un caso probable o confirmado en los dos días previos o en los 14 días posteriores al comienzo de los síntomas de este caso, de una de las siguientes formas:

- Contacto cara a cara con un caso probable o confirmado a menos de un metro de distancia y por más de 15 minutos.

- Contacto físico directo con un caso probable o confirmado.

- Estar al cuidado de un paciente con enfermedad COVID-19 probable o confirmada, sin utilizar el equipo de protección adecuado.

- Cualquier otra situación señalada como un riesgo a nivel local.

Para disminuir la diseminación del virus SARS-CoV-2 y "aplanar la curva" epidémica, y así evitar que haya un colapso en los sistemas de atención en salud, los Centros para el Control y la Prevención de Enfermedades, CDC (del inglés, Centers for Disease Control and Prevention), recomiendan el distanciamiento social, lo cual describen como evitar las multitudes y mantener un espacio de 2 metros, en particular con aquellos que muestren signos de la enfermedad, como tos, estornudos, fiebre o malestar general, debido a que se considera que la principal vía de transmisión del virus es de persona a persona, mediante el contacto directo, gotas de saliva, fómites, y posiblemente por aerosoles $[3,18,19]$. El CDC también recomienda el lavado frecuente de las manos como medida preventiva. La permanencia viable del virus en superficies se ha estimado hasta de 3 días, dependiendo del inóculo, muy similar a la del virus causante del SARS [20].

Recientemente se ha encontrado evidencia de excreción fecal del virus, lo cual sugiere que la transmisión por vía entero-fecal también sea posible [2123]. De igual forma, se ha reportado transmisión del virus a partir de casos asintomáticos [24,25].

El periodo de incubación es variable, pero generalmente dura de 2 a 7 días, aunque a veces puede ser hasta de 2 semanas [3,26-28]; esto sugiere un periodo de cuarentena ideal mínimo de 14 días [28]. Se han establecido modelos matemáticos que asumen que la transmisión comienza entre 1 y 2 días antes del inicio de los síntomas [29]. La enfermedad parece afectar un poco más a hombres que a mujeres [30], la mayoría de los afectados tienen edades que varían entre 30 y 79 años en el $87 \%$ de los casos [28,31], y se ha observado una menor susceptibilidad a COVID-19 en los menores, con tasas de enfermedad del $1 \%$ en los niños y jóvenes menores de 19 años, a pesar de tener cargas virales altas cuando se infectan [1,32,33]. Se estima que aproximadamente entre el $7 \%$ y el $10 \%$ de los casos progresan a enfermedad severa, y que la tasa de letalidad pueda estar entre 1\% y $3 \%$, aunque estas tasas varían dependiendo de las comorbilidades en los pacientes y de la ubicación geográfica, [34,35]; sin embargo, estas tasas son estimadas con base en el número de muertes al presente y en el número de casos confirmados actuales. El número resultante no representa una tasa de letalidad real, pues la confirmación del diagnóstico se hace días o incluso semanas antes de conocerse si esos pacientes sobrevivirán o no. Es decir, las muertes se producen luego de varios días de haberse confirmado el 
diagnóstico, en tanto que hay casos nuevos confirmados cada día [36,37]. Además, se deben tener en cuenta los casos asintomáticos y los sintomáticos no confirmados con una prueba diagnóstica, lo cual finalmente se puede traducir como unas tasas de letalidad estimadas mayores a las reales.

El número reproductivo básico $\left(R_{0}\right)$ del virus en las etapas iniciales de la infección, se ha calculado entre 2,2 y 3,5 (95\% IC: 1,4-3,9), lo que indica que cada individuo puede potencialmente transmitir el virus a dos o tres personas $[28,30,38]$, valor similar al del SARS-CoV y mayor que el del MERS-CoV, calculados en 2 a 3, y $<1$, respectivamente [31] (tabla 2 ). El periodo de contagiosidad del SARSCoV-2 es prologado en comparación con el de otros virus causantes de in-

\begin{tabular}{|c|c|c|c|}
\hline Característica & SARS & MERS & COVID-19 \\
\hline Aparición del brote & $\begin{array}{l}\text { Guangdong, China } \\
\text { (noviembre 2002) }\end{array}$ & $\begin{array}{l}\text { Zarga, Jordania } \\
\text { (abril 2012) }\end{array}$ & $\begin{array}{l}\text { Wuhan, China } \\
\text { (diciembre 2019) }\end{array}$ \\
\hline Virus causante & SARS-CoV & MERS-CoV & SARS-CoV-2 \\
\hline $\begin{array}{l}\text { Número de países/regiones } \\
\text { afectados }\end{array}$ & 29 & 26 & 185 \\
\hline Receptor celular & ACE2 & $\begin{array}{l}\text { Dipeptidil peptidasa } \\
4(\mathrm{CD} 26)\end{array}$ & ACE2 \\
\hline Periodo de incubación (días) & $\begin{array}{l}4,6 \\
\text { (rango entre } 2 \text { y } 7 \text { ) }\end{array}$ & $\begin{array}{l}5,2 \\
\text { (rango entre } 2 \text { y } 13 \text { ) }\end{array}$ & $\begin{array}{l}5,2 \\
\text { (rango entre } 2 \text { y } 14)\end{array}$ \\
\hline $\begin{array}{l}\text { Número reproductivo básico } \\
\left(R_{0}\right) \text { del virus causante }\end{array}$ & 2 a 3 & $<1$ & 2,2 a 3,5 \\
\hline Letalidad estimada (\%) & $9,6 \%$ & $35 \%$ a $40 \%$ & $1 \%$ a $3 \%$ \\
\hline $\begin{array}{l}\text { Totalidad de casos } \\
\text { confirmados }\end{array}$ & $\begin{array}{l}8.096 \\
\text { (a diciembre 31, } \\
2003 \text { ) } \\
\text { No se han reportado } \\
\text { casos nuevos }\end{array}$ & $\begin{array}{l}2.519 \\
\text { (a enero 31, 2020) } \\
\text { Caso más reciente } \\
\text { reportado en enero } \\
2020\end{array}$ & $\begin{array}{l}2.626 .321 \\
\text { (a abril 24, 2020) }\end{array}$ \\
\hline Letalidad total & $\begin{array}{l}774 \text { (a diciembre 31, } \\
2003 \text { ) }\end{array}$ & $\begin{array}{l}866 \text { (a enero } 31, \\
2020)\end{array}$ & $\begin{array}{l}\text { 181.938 (a abril 24, } \\
2020 \text { ) }\end{array}$ \\
\hline Síntomas comunes & $\begin{array}{l}\text { Fiebre, tos, dolor de } \\
\text { garganta, mialgias, } \\
\text { cefalea, diarrea, } \\
\text { disnea }\end{array}$ & $\begin{array}{l}\text { Fiebre, tos, disnea, } \\
\text { mialgias, vómito, } \\
\text { diarrea }\end{array}$ & $\begin{array}{l}\text { Fiebre, tos, disnea, } \\
\text { mialgias, neumonía, } \\
\text { fatiga }\end{array}$ \\
\hline $\begin{array}{l}\text { Pruebas diagnósticas } \\
\text { utilizadas }\end{array}$ & RRT-PCR, serología & RRT-PCR, serología & rRT-PCR, serología \\
\hline $\begin{array}{l}\text { Algunos tratamientos } \\
\text { utilizados, no específicos }\end{array}$ & $\begin{array}{l}\text { Ribavirina, } \\
\text { lopinavir, ritonavir, } \\
\text { corticoesteroides, } \\
\text { inmunoglobulina } \\
\text { intravenosa, plasma } \\
\text { de pacientes } \\
\text { convalecientes, IFN }\end{array}$ & $\begin{array}{l}\text { Ribavirina, } \\
\text { lopinavir, ritonavir, } \\
\text { corticoesteroides, } \\
\text { inmunoglobulina } \\
\text { intravenosa, plasma } \\
\text { de pacientes } \\
\text { convalecientes, IFN }\end{array}$ & $\begin{array}{l}\text { Hidroxicloroquina, } \\
\text { cloroquina, } \\
\text { ribavirina, lopinavir, } \\
\text { ritonavir, remdesivir }\end{array}$ \\
\hline
\end{tabular}

COVID-19: enfermedad por coronavirus-2019; SARS: síndrome respiratorio agudo severo; MERS: síndrome respiratorio del Medio Oriente; ACE2: enzima convertidora de angiotensina 2; rRT-PCR: reacción en cadena de la polimerasa con transcriptasa reversa en tiempo real; IFN: interferón. 
fecciones respiratorias agudas; usualmente inicia uno o dos días antes del comienzo de los síntomas y se prolonga por varias semanas, siendo mayor en los casos más graves. Se estima que la mediana de la excreción viral es de 20 días aproximadamente (rango entre 8 a 37 días) [39].

Entre los factores de riesgo para enfermedad severa y muerte, se ha encontrado que la edad avanzada es tal vez el principal [40]. Otros factores también asociados son las comorbilidades, como diabetes, hipertensión, enfermedad cardiovascular y cáncer $[1,32,33,39]$.

La transmisión vertical, aunque se ha sospechado, hasta el momento no se ha confirmado. El estudio de Chen y colaboradores [41] evaluó 9 mujeres gestantes con diagnóstico confirmado de neumonía por SARS-CoV-2, con parto por cesárea. Se buscó el virus en muestras de 6 pacientes de líquido amniótico, cordón umbilical, leche materna y en hisopados faríngeos de los neonatos, pero los resultados fueron negativos en todos los casos. Sin embargo, esto no indica que no pueda existir una posible infección perinatal, como se ha sugerido previamente [27].

Las infecciones nosocomiales han mostrado también afectar la carga a los sistemas de salud. En un estudio por Wang y colaboradores [38], que se realizó en 138 pacientes hospitalizados, mostró que el $41 \%$ de los pacientes habían tenido una posible transmisión de origen nosocomial.

La mayoría de los pacientes tienen un pronóstico bueno [31], aunque menos favorable para aquellos pacientes de edad avanzada y comorbilidades, como las mencionadas previamente.

\section{Patogénesis}

EI SARS-CoV-2 entra a la célula utilizando como receptor a la ACE2 [3,42], al igual que el virus SARS-CoV, causante del SARS; sin embargo, la afinidad del SARS-CoV-2 por la ACE2 es de 10 a 20 veces mayor que la del SARS-CoV [3]. La ACE2 se encuentra presente en mayores cantidades en el riñón, los pulmones y el corazón, y participa en la trasformación de la angiotensina I en angiotensina 1-9, y de la angiotensina II en angiotensina 1-7. Estos productos finales tienen efectos vasodilatadores que reducen la presión arterial, con efecto protector frente a la hipertensión, la arteriosclerosis, y otros procesos vasculares y pulmonares. Se ha observado que los casos graves de COVID-19 presentan niveles de angiotensina II altos, y que sus niveles se correlacionan con la carga viral y el daño pulmonar [29].

Por otra parte, se ha observado que el SARS-CoV-2 induce la producción de daño cardiaco agudo e insuficiencia cardiaca, con un aumento en los niveles de troponina asociados a una mayor mortalidad $[39,43,44]$. En un estudio reciente llevado a cabo por Guo y colaboradores [44], se encontró que de 187 pacientes con diagnóstico confirmado de COVID-19, el 27,8\% tenía daño cardiaco asociado a la infección. La alta incidencia observada de síntomas cardiovasculares parece relacionada con la respuesta inflamatoria sistémica. Se sugiere que en gran parte, la virulencia asociada a la infección por SARS-CoV-2 es debida a su poderosa capacidad de activar una respuesta inmune, con una cascada de citoquinas inflamatorias, como uno de los mecanismos para el daño a nivel de órganos $[35,45]$. 


\section{Manifestaciones clínicas}

El curso de la COVID-19 es variable y va desde la infección asintomática hasta la neumonía grave que requiere ventilación asistida y es frecuentemente fatal (figura 5). La forma asintomática y las presentaciones leves son más comunes en niños, adolescentes y adultos jóvenes, en tanto que las formas graves se observan más en los mayores de 65 años y en personas con condiciones crónicas como diabetes, enfermedad pulmonar obstructiva crónica (EPOC), enfermedad cardiovascular o cerebrovascular, e hipertensión, entre otras $[40,46,47]$.

Los síntomas más comunes, fiebre y tos, están presentes en la mayoría de los pacientes, pero no en todos los casos sintomáticos. La fiebre puede ser alta y prolongada, lo que se asocia a desenlace desfavorable [40]. La tos puede ser seca o productiva con igual frecuencia, y a veces se acompaña de hemoptisis. La fatiga es común, y las mialgias y la cefalea ocurren entre el $10 \%$ y $20 \%$ de los casos. La disnea se ha reportado con frecuencias muy variables, desde $8 \%$ hasta más del $60 \%$, dependiendo de los criterios de inclusión de cada estudio; la disnea puede aparecer desde el segundo día pero puede tardar hasta 17 días, y dicha aparición tardía parece asociarse a desenlaces más graves [47]. Otros síntomas de afectación del tracto respiratorio alto, como dolor de garganta, congestión nasal y rinorrea, se presentan en menos del $15 \%$ de los casos $[40,47,48]$.

Las manifestaciones gastrointestinales, como náuseas, vómito, malestar abdominal y diarrea, se presentan tempranamente entre el $10 \%$ y $20 \%$ de los pacientes. La anorexia se manifiesta en uno de cada cuatro casos, y es más frecuente a partir de la segunda semana de la enfermedad $[40,47]$. Estos síntomas digestivos se correlacionan con mayor frecuencia de detección y mayor carga viral en materia fecal [49]. Las alteraciones de los sentidos del gusto (ageusia) y del olfato (anosmia) también son frecuentes [50].

Entre las complicaciones más comunes de la COVID-19 se menciona la neumonía, presente virtualmente en todos los casos graves, el síndrome de dificultad respiratoria del adulto (SDRA), la miocarditis, el daño renal agudo y las sobreinfecciones bacterianas, frecuentemente en la forma de choque séptico $[40,47]$. Los trastornos de la coagulación, expresados por la prolongación del tiempo de protrombina, el aumento del dímero $D$ y la disminución en el recuento de plaquetas, han llevado a pensar que la coagulación intravascular diseminada es uno de los fenómenos comunes en los casos graves, por lo que algunos recomiendan anticoagulación temprana. El compromiso de múltiples órganos se expresa por la alteración de las pruebas bioquímicas, como la elevación de las aminotransferasas, deshidrogenasa láctica, creatinina, troponinas, proteína $C$ reactiva y procalcitonina [40].

\section{Diagnóstico}

El diagnóstico de COVID-19 muestra limitaciones. Al inicio del brote epidémico se utilizó la secuenciación del genoma viral como método diagnóstico, pero esta técnica es costosa y poco práctica para el procesamiento de grandes cantidades de muestras $[31,42]$. Inicialmente también se desarrolló una prueba de ELISA para 

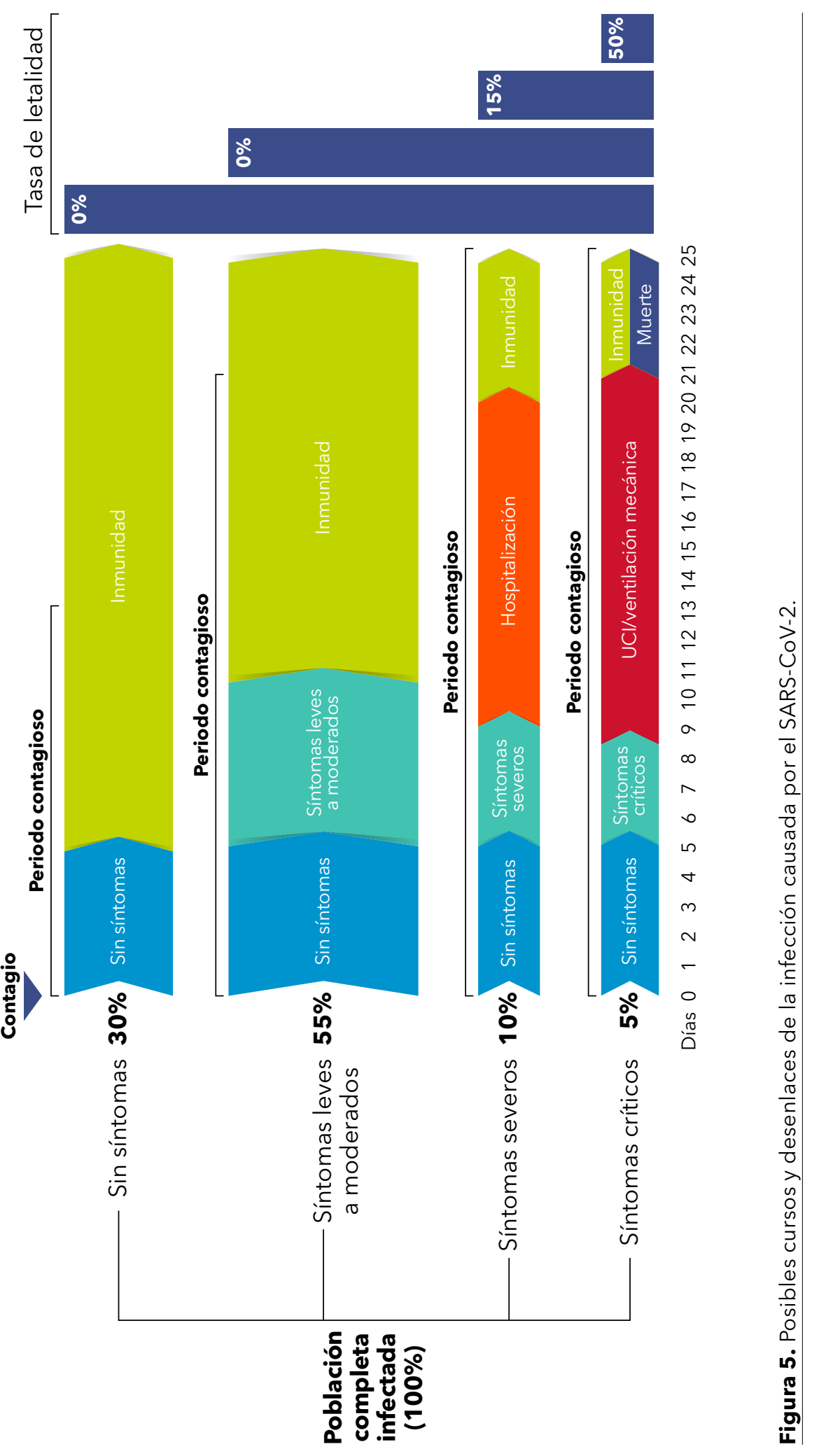
detectar IgM e IgG contra la proteína de la nucleocápside viral del SARSCoV-2, pero tiene el inconveniente de que puede arrojar resultados falsos positivos al detectar anticuerpos contra otros coronavirus que causan resfriado común. También se han desarrollado pruebas serológicas rápidas con sensibilidades y especificidades variables [51-53]. Las pruebas de ELISA basadas en la nucleoproteína $(N)$ y en la proteína $S$ de unión al receptor, parecen ser más prometedoras $[42,54]$. En general, los estudios realizados hasta ahora, con los estuches comerciales disponibles y las pruebas de ELISA caseras, muestran que la seroconversión ( $\lg M$ e $\lg G$ ) ocurre en los primeros 7 días de iniciados los síntomas en el $40 \%$ a $50 \%$ de los pacientes, y para el día 15 en casi el $100 \%$ de ellos, aunque los resultados arrojan gran variabilidad en cuanto al momento de aparición de los anticuerpos, sensibilidad y especificidad [55-57] (figura 6).

Hasta el momento, la FDA (del inglés, Food and Drug Administration), ante la emergencia, ha aprobado 6 pruebas serológicas, 2 de ellas rápidas, que detectan anticuerpos contra el SARSCoV-2. Sin embargo, de acuerdo con la OMS, no hay aún una prueba serológica que como prueba única pueda ser utilizada para el diagnóstico, y ha limitado su uso solo para algunos laboratorios que realizan pruebas de complejidad moderada a alta [58].

Para el diagnóstico de rutina hoy en día, se utiliza la búsqueda del RNA viral en las muestras de secreciones respiratorias, saliva y de hisopado nasal o faríngeo, mediante la prueba de reacción en cadena de la polimerasa con transcriptasa reversa en tiempo real (rRT-PCR) $[47,59,60]$. Hasta el momento, en Colombia, esta prueba molecular se hace en laboratorios de referencia o de investigación autorizados por el gobierno, pero es previsible que pronto estará disponible en múltiples sitios. Se han desarrollado pruebas para detectar los genes RdRP y E del genoma viral, con el fin de hacerlas más específicas para el SARS-CoV-2 [60]. Otras pruebas moleculares se enfocan en el gen $\mathrm{N}$, el cual junto con los anteriormente mencionados, son los genes que se predicen como más estables. El 14 de marzo, la Universidad Johns Hopkins anunció haber desarrollado una prueba que permitirá en poco tiempo el tamizaje masivo de hasta 1.000 personas al día, por parte de las entidades de salud, con resultados rápidos, en 24 horas o menos [61].

Se ha demostrado que la carga viral por rRT-PCR es alta en la mayoría de los pacientes desde el inicio o incluso desde antes de la aparición de los síntomas, haciendo pico después de 3 a 5 días, para luego comenzar a disminuir de forma significativa alrededor del día 10, para bajar a niveles no detectables alrededor del día 21 (figura 6), aunque se observa variabilidad no solo a nivel individual, sino entre las diferentes muestras en un mismo paciente $[22,62,63]$. Además, se ha reportado que pacientes dados de alta por tener la rRT-PCR negativa, han regresado por recaídas varios días después y han vuelto a ser positivos por esta prueba. En efecto, varios trabajos muestran que la excreción viral puede ser intermitente, ya sea por la persistencia del virus en órganos, una posible reinfección o por resultados falsos negativos en la rRT-PCR [54,64-66], lo que ha llevado a darse la recomendación de no dar de alta al paciente, a menos que sea negativo en dos muestras tomadas en diferentes días [54]. También se ha encontrado que la carga viral de pacientes asintomáticos y sintomáticos tiene 


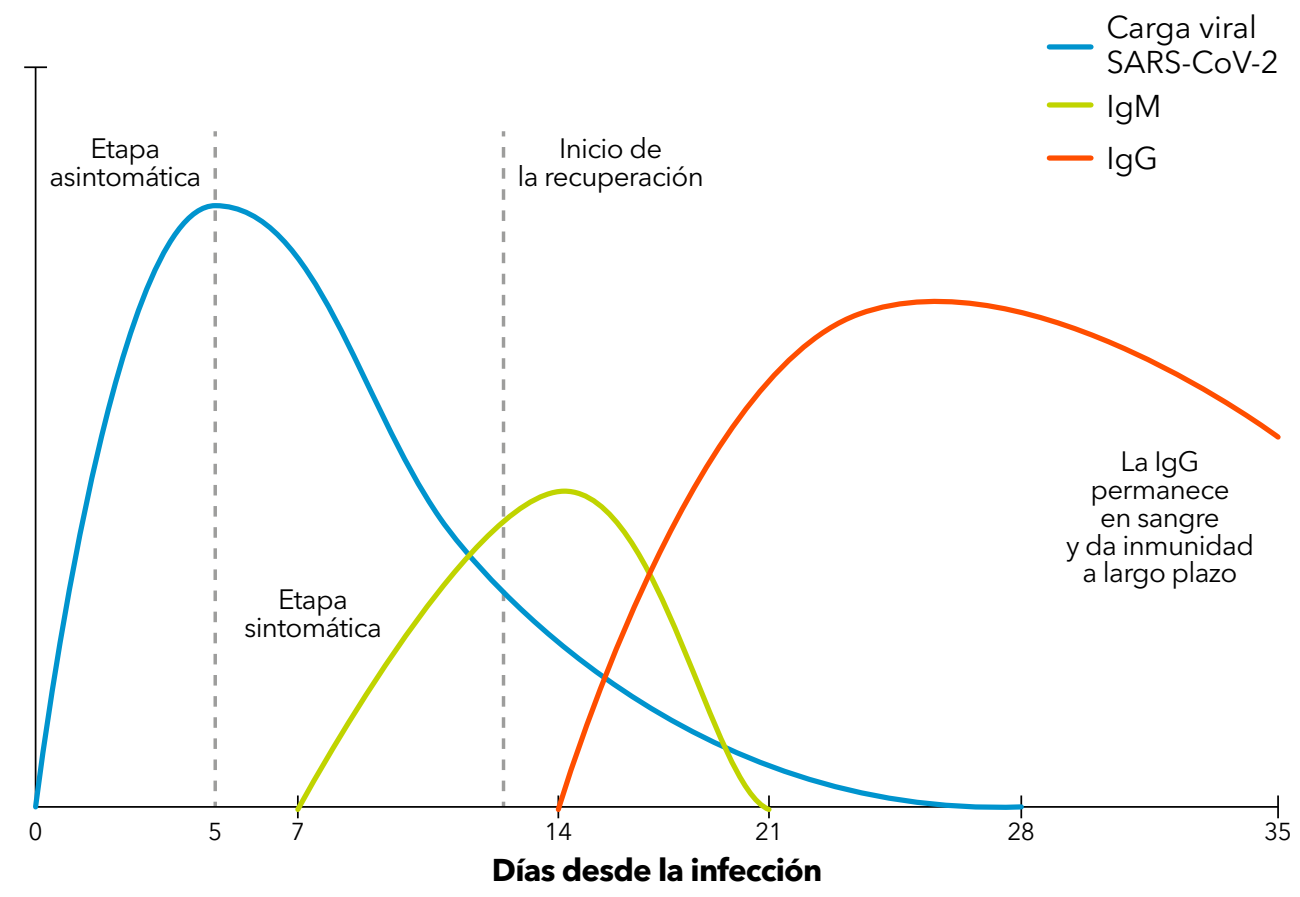

Figura 6. Detección de la carga viral y de los anticuerpos generados por el hospedero en la historia natural de la infección por SARS-CoV-2, con la información hasta la fecha.

valores similares $[22,25,67]$. Estos hallazgos podrían explicar en gran parte la facilidad con la cual esta infección se transmite, dificultando unas medidas de control eficientes, diferentes al distanciamiento social.

Aunque la rRT-PCR es una prueba muy sensible, también tiene limitaciones. Entre ellas, su resultado depende de que las muestras tengan suficiente cantidad de RNA viral, la pequeña ventana de detección a partir de las muestras de hisopados nasofaríngeos, la diferencia en los límites de detección de acuerdo con los primers utilizados, los falsos positivos por la contaminación de las muestras durante su procesamiento, y la variabilidad en la excreción viral en cada paciente, demostrada en resultados negativos de la prueba, intercalados con resultados positivos en un mismo paciente
$[31,68]$. Esto hace que una prueba serológica bien fundamentada sea una necesidad como prueba complementaria a la molecular. Además, serviría para evaluar a aquellos contactos con casos sospechosos o probables, e incluso confirmados, que estén cumpliendo cuarentena en sus hogares, al igual que para los estudios epidemiológicos, y eventualmente para evaluar la eficacia de las vacunas. En la figura 7 se observa un algoritmo para el diagnóstico de COVID-19, ante la sospecha de un paciente infectado por SARS-CoV-2, de acuerdo con el Consenso Colombiano de Atención, Diagnóstico y Manejo de la Infección por SARS-COV-2/COVID-19 en Establecimientos de Atención de la Salud [69].

En la tabla 3 se observa cómo podría ser la interpretación de los resultados de la prueba molecular y serológica, 


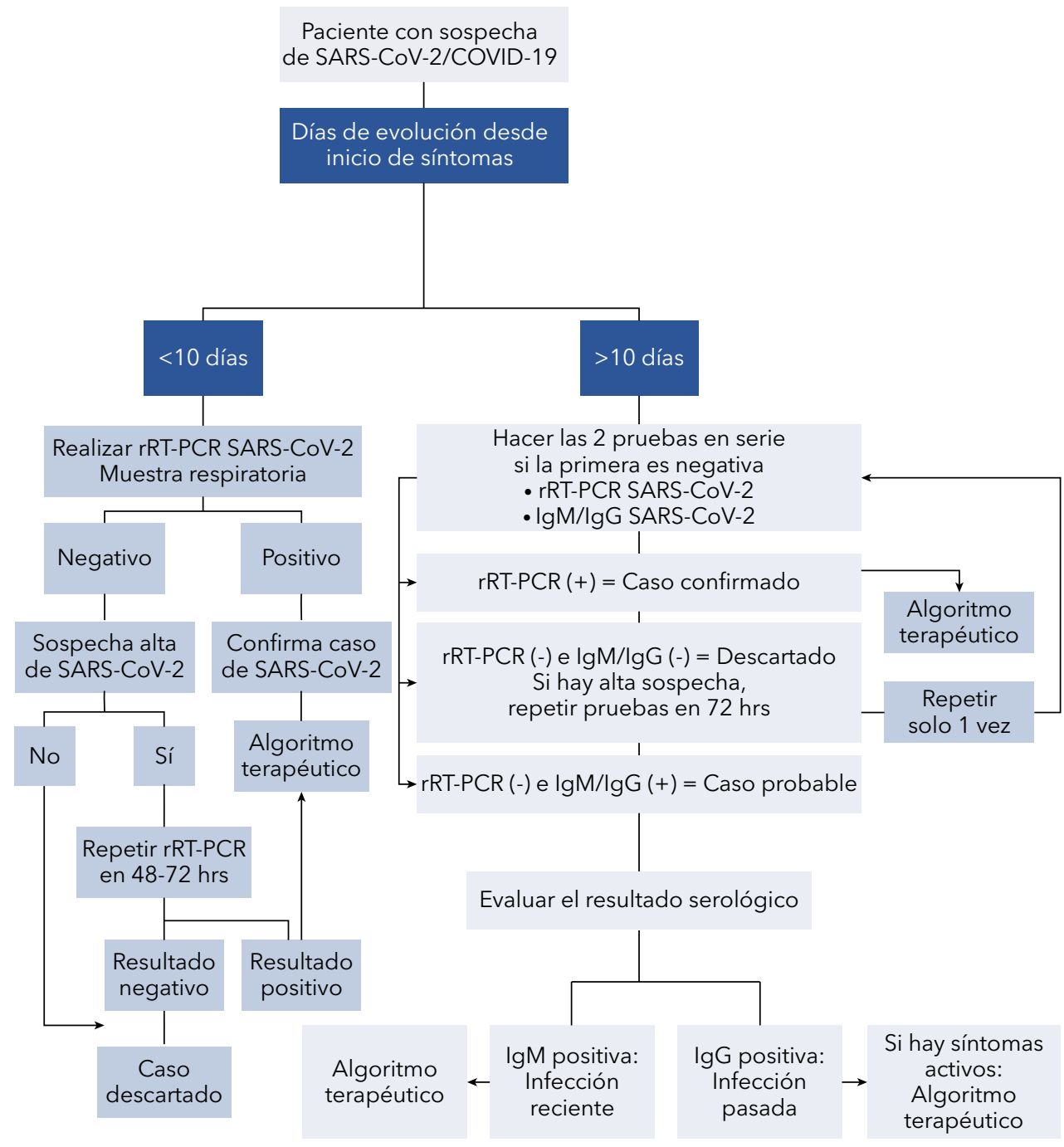

Figura 7. Algoritmo para el diagnóstico ante la sospecha de un paciente infectado por SARSCoV-2, de acuerdo con el Consenso Colombiano de Atención, Diagnóstico y Manejo de la Infección por SARS-COV-2/COVID-19 en Establecimientos de Atención de la Salud [69]. rRTPCR: reacción en cadena de la polimerasa con transcriptasa reversa en tiempo real.

realizadas de forma paralela; la prueba molecular demuestra ser la ideal en la fase temprana, en tanto que la serológica demuestra mayor utilidad en la fase más avanzada. Sin embargo, debido a que en muchas instancias es difícil determinar en qué fase se encuentra el paciente, la combinación de ambas pruebas mejoraría la probabilidad de un diagnóstico eficaz y oportuno de la infección $[56,57]$. En un estudio realizado por Guo y colaboradores [70] se encontró no solo que la eficiencia diagnóstica de la detección de lgM por ELISA era mayor después del día 5 a 6 del inicio de los síntomas, en comparación con la de la rRT-PCR (51,9\%), sino que al combinarse el uso de am- 
bas pruebas, se aumentaba la capacidad diagnóstica a 98,6\%.

En cuanto a las pruebas inespecíficas de laboratorio clínico, se ha encontrado que la linfopenia es uno de los hallazgos más típicos, en particular de los linfocitos $T[33,71]$. La mitad de los pacientes muestran también aumento de las enzimas hepáticas alanino aminotransferasa (ALT) y aspartato aminotransferasa (AST), y un gran porcentaje de los afectados presentan niveles altos de proteína $C$ reactiva, dímero $D, y$ de las enzimas lactato deshidrogenasa (LDH) y creatina quinasa (CPK) $[28,31,33,71]$, además de aumento del tiempo de protrombina (TP) $[31,40]$. Citoquinas como la interleuquina (IL)-6, la IL-10 y el factor de necrosis tumoral alfa (TNF- $\alpha$ ), también se encuentran usualmente elevadas, de acuerdo con el estado inmune del paciente [35]; vale la pena mencionar que esta respuesta inmune del paciente es de vital importancia para la resolución de la enfermedad, a la vez que contribuye con la inmunopatogénesis asociada, si no es regulada en forma precisa [3].
Los hallazgos radiográficos en el tórax pueden tomar el patrón de opacidad en vidrio esmerilado, infiltrados irregulares en uno o ambos campos pulmonares, y menos frecuentemente, infiltrado intersticial [40]. En la tomografía es aún más común encontrar imágenes en vidrio esmerilado, infiltrados, engrosamiento de los septos y consolidaciones $[33,40,48]$.

\section{Tratamiento}

Hasta el momento no hay un tratamiento antiviral específico aprobado por la FDA [72]. Los pacientes con cuadros leves deben ser manejados sintomáticamente y aislados en su casa. Los casos graves son aislados en los centros de atención, y el tratamiento es enfocado principalmente al alivio de los síntomas generales, la oxigenoterapia y, en los casos críticos, al soporte respiratorio, con o sin ventilación mecánica [3]. Se han utilizado varios medicamentos antivirales; entre ellos, ribavirina, la combinación de lopinavir/ritonavir [73] y remdesivir $[3,28,33,45,72,74]$. Sin

Tabla 3. Posible interpretación de los resultados de la rRT-PCR y las pruebas serológicas determinadas de forma paralela

\begin{tabular}{|c|c|c|c|}
\hline \multicolumn{3}{|c|}{ Resultados de las pruebas } & \multirow{2}{*}{ Interpretación clínica } \\
\hline rRT-PCR & $\lg M$ & IgG & \\
\hline+ & - & - & El paciente puede estar en la etapa temprana de la infección \\
\hline+ & + & - & El paciente puede estar en una etapa intermedia de la infección \\
\hline+ & + & + & El paciente está en la etapa tardía, pero aún activa de la infección \\
\hline+ & - & + & $\begin{array}{l}\text { El paciente puede estar en la etapa tardía o recurrente de la } \\
\text { infección }\end{array}$ \\
\hline- & + & - & $\begin{array}{l}\text { El paciente puede estar en la etapa intermedia de la infección y el } \\
\text { resultado de la rRT-PCR puede ser falso negativo }\end{array}$ \\
\hline- & - & + & El paciente puede tener una infección resuelta o antigua \\
\hline- & + & + & $\begin{array}{l}\text { El paciente puede estar en la etapa de recuperación de la infección } \\
\text { o el resultado de la rRT-PCR puede ser falso negativo }\end{array}$ \\
\hline
\end{tabular}

rRT-PCR: reacción en cadena de la polimerasa con transcriptasa reversa en tiempo real 
embargo, se deben esperar los resultados que arrojen los múltiples ensayos clínicos que se están llevando a cabo, antes de poderse determinar una terapia antiviral efectiva. A la fecha de publicación de este artículo, de acuerdo con los estudios clínicos registrados en ClinicalTrials.gov, WHO ICTRP, EU Clinical Trials Register y en Cochrane Central Register of Controlled Trials [75], los tratamientos que se están evaluando incluyen los programas de prevención de la diseminación de la infección, la terapia con antivirales [74], antimaláricos (cloroquina e hidroxicloroquina) $[3,72,76]$, inmunomoduladores [77], y la terapia biológica con plasma de pacientes convalecientes [3,31,78-80], entre otros. También, se viene utilizando interferón beta (IFN-ß) [2], corticoides [74], antibióticos y vitamina C $[33,81]$. Recientemente, se ha encontrado que la combinación de remdesivir con cloroquina tiene efecto inhibidor del virus in vitro [3].

La FDA está actualmente motivando a las personas que se han recuperado totalmente de COVID-19, para que donen plasma, el cual puede ayudar de forma inmediata a la recuperación de pacientes [78,82-84]. De manera similar, la EBA (del ingles, European Blood Alliance) ha comenzado una investigación con plasma convaleciente [85], al igual que varias entidades en nuestro medio, para evaluar la efectividad y seguridad del plasma convaleciente en los pacientes afectados por COVID-19.

Desde el inicio de la aparición del SARS-CoV-2, a nivel mundial se está trabajando en el desarrollo de una vacuna efectiva y segura contra el virus, y los esfuerzos se han enfocado en la proteína $S$, que es la que se une al receptor celular, la ACE2, en los pulmones, como ya se mencionó. Entre las opciones se encuentran las que utilizan la proteína $S$ recombinante purificada y fragmentos de mRNA o DNA de la proteína $S$ que puedan inducir la formación de anticuerpos [2,29,31]. A abril 20 de 2020 ya se encontraban seis vacunas en fase 1 de investigación clínica y una en fase 2 [86].

\section{Conclusión}

En conclusión, los datos recogidos hasta el momento indican que la COVID-19 es una enfermedad causada por un coronavirus altamente transmisible, con una tasa de letalidad entre baja y moderada, dependiendo de las comorbilidades y la situación geográfica. Pareciera que esta enfermedad golpea más fuerte a los sistemas de salud que a los individuos, teniendo como resultado el colapso en los centros de atención de las regiones más afectadas, lo cual a su vez contribuye con un retraso en la atención primaria a los pacientes.

La tarea a la que se enfrentan ahora las diferentes entidades gubernamentales consiste en tratar de equilibrar las medidas de aislamiento preventivo con aquellas destinadas a aminorar el daño económico y social, generado por el aislamiento obligatorio y el cierre de fronteras. Las esperanzas a corto plazo están puestas en el desarrollo de una prueba serológica óptima, con la suficiente especificidad diagnóstica para que diferencie el SARS-CoV-2 de los otros coronavirus, la cual permitiría que el personal médico y paramédico con inmunidad demostrada, pudiera atender a los pacientes con sospecha o afectados por COVID-19 sin temor a infectarse, a la vez que permitiría al resto de la población inmune regresar a sus puestos de trabajo, para lentamente iniciarse el restablecimiento de la economía mundial y el orden social, trastornados por una pandemia. 


\section{Agradecimientos}

A todo el personal de la salud por su incansable labor durante esta pandemia causada por el virus SARS-CoV-2.

\section{Referencias}

1. Wu Z, McGoogan JM. Characteristics of and important lessons from the coronavirus disease 2019 (COVID-19) outbreak in China: Summary of a report of 72314 cases from the Chinese Center for Disease Control and Prevention. JAMA 2020. https://doi.org/10.1001/ jama.2020.2648.

2. Khan S, Siddique $R$, Adnan-Shereen $M$, Ali A, Liu J, Bai $\mathbf{Q}$, et al. The emergence of a novel coronavirus (SARS-CoV-2), their biology and therapeutic options. J Clin Microbiol 2020. [Epub ahead of print] 11 de marzo de 2020. https://doi.org/https://doi.org/10.1128/ JCM.00187-20.

3. Guo YR, Cao QD, Hong ZS, Tan YY, Chen SD, Jin HJ, et al. The origin, transmission and clinical therapies on coronavirus disease 2019 (COVID-19) outbreak - an update on the status. Mil Med Res 2020;7:11. https://doi.org/10.1186/ s40779-020-00240-0.

4. Lu R, Zhao $X$, Li J, Niu P, Yang B, Wu H, et al. Genomic characterisation and epidemiology of 2019 novel coronavirus: implications for virus origins and receptor binding. Lancet 2020;395:565-574. https://doi.org/10.1016/ S0140-6736(20)30251-8.

5. Adhanom-Ghebreyesus T. WHO DirectorGeneral's opening remarks at the media briefing on COVID-19 - 11 March 2020. Ginebra, Suiza: World Health Organization; 2020. Acceso 4 de abril de 2020. Disponible en https:// www.who.int/dg/speeches/detail/who-director-general-s-opening-remarks-at-the-mediabriefing-on-covid-19---11-march-2020.

6. Gorbalenya AE, Baker SC, Baric RS, de Groot RJ, Drosten C, Gulyaeva AA, et al. The species Severe acute respiratory syndrome-related coronavirus: classifying 2019-nCoV and naming it SARS-CoV-2. Nat Microbiol 2020;5:536-544. https://doi.org/10.1038/s41564-020-0695-z.
7. Pal M, Berhanu G, Desalegn C, Kv R. Severe acute respiratory syndrome coronavirus-2 (SARS-CoV-2): An update. Cureus 2020;12:e7423. https://doi.org/10.7759/cureus. 7423 .

8. Chan JF-W, Kok K-H, Zhu Z, Chu H, To KKW, Yuan S, et al. Genomic characterization of the 2019 novel human-pathogenic coronavirus isolated from a patient with atypical pneumonia after visiting Wuhan. Emerg Microbes Infect 2020;9:221-236. https://doi.org/10.1080/2222 1751.2020.1719902.

9. American Veterinary Medical Association (AVMA). Coronavirus: Detailed taxonomy. Schaumburg, IL: AVMA; 2020. Acceso 4 de abril de 2020. Disponible en https://www.avma.org/ sites/default/files/2020-02/AVMA-Detailed-Coronoavirus-Taxonomy-2020-02-03.pdf.

10. Mesel-Lemoine $M$, Millet J, Vidalain PO, Law H, Vabret A, Lorin V, et al. A human coronavirus responsible for the common cold massively kills dendritic cells but not monocytes. J Virol 2012;86:7577-7587. https://doi.org/10.1128/ JVI.00269-12.

11. Fehr AR, Perlman S. Coronaviruses: an overview of their replication and pathogenesis. Methods Mol Biol 2015;1282:1-23. https://doi. org/10.1007/978-1-4939-2438-7_1.

12. Mousavizadeh L, Ghasemi S. Genotype and phenotype of COVID-19: Their roles in pathogenesis. J Microbiol Immunol 2020. [Epub ahead of print] 31 de marzo de 2020. https://doi.org/ https://doi.org/10.1016/j.jmii.2020.03.022.

13. Shereen MA, Khan S, Kazmi A, Bashir N, Siddique R. COVID-19 infection: Origin, transmission, and characteristics of human coronaviruses. J Adv Res 2020;24:91-98. https://doi. org/10.1016/j.jare.2020.03.005.

14. Johns Hopkins University \& Medicine. Coronavirus COVID-19 Global Cases by the Center for Systems Science and Engineering (CSSE) at Johns Hopkins University (JHU). Baltimore, Maryland: Coronavirus Resource Center. Acceso 30 de marzo de 2020. Disponible en https:// coronavirus.jhu.edu/map.html.

15. Worldometers. info. Covid-19 coronavirus pandemic. Delaware, USA: Dadax Limited; 2020. Acceso 30 de marzo de 2020. Disponible en https://www.worldometers.info/coronavirus/. 
16. Instituto Nacional de Salud. Coronavirus (COVID - 2019) en Colombia. Bogotá, D.C.: Instituto Nacional de Salud; 2020. Acceso 30 de marzo de 2020. Disponible en https:// www.ins.gov.co/Noticias/Paginas/Coronavirus.aspx.

17. World Health Organization (WHO). Coronavirus disease 2019 (COVID-19). Situation Report-86. Ginebra, Suiza: WHO; 2020. Acceso 16 de abril de 2020. Disponible en https:// www.who.int/docs/default-source/coronaviruse/situation-reports/20200415-sitrep-86-covid-19.pdf?sfvrsn=c615ea20_6.

18. Van Cuong L, Giang HTN, Linh LK, Shah J, Van Sy L, Hung TH, et al. The first Vietnamese case of COVID-19 acquired from China. Lancet Infect Dis 2020;20:408-409. https://doi. org/10.1016/S1473-3099(20)30111-0.

19. World Health Organization (WHO). Coronavirus disease 2019 (COVID-19). Situation Report-31. Ginebra, Suiza: WHO; 2020. p. 7. Acceso 18 de marzo de 2020. Disponible en https://www.who.int/docs/default-source/coronaviruse/situation-reports/20200220-sitrep31-covid-19.pdf?sfvrsn=dfd11d24_2.

20. van Doremalen $N$, Bushmaker $T$, Morris $D H$, Holbrook MG, Gamble A, Williamson BN, et al. Aerosol and surface stability of SARSCoV-2 as compared with SARS-CoV-1. N Engl J Med 2020:p. 3. https://doi.org/10.1056/NEJMc2004973.

21. Heymann DL, Shindo N, Scientific WHO, Technical Advisory Group for Infectious H. COVID-19: what is next for public health? Lancet 2020;395:542-545. https://doi.org/10.1016/ S0140-6736(20)30374-3.

22. Holshue $M L$, DeBolt $C$, Lindquist $S$, Lofy KH, Wiesman J, Bruce $\mathbf{H}$, et al. First case of 2019 novel coronavirus in the United States. N Engl J Med 2020;382:929-936. https://doi. org/10.1056/NEJMoa2001191.

23. Yeo C, Kaushal S, Yeo D. Enteric involvement of coronaviruses: is faecal-oral transmission of SARS-CoV-2 possible? Lancet Gastroenterol Hepatol 2020;5:335-337. https://doi. org/10.1016/S2468-1253(20)30048-0.

24. Rothe $C$, Schunk M, Sothmann P, Bretzel G, Froeschl G, Wallrauch $\mathbf{C}$, et al. Transmission of 2019-nCoV infection from an asymptomatic con- tact in Germany. N Engl J Med 2020;382:970-

971. https://doi.org/10.1056/NEJMc2001468.

25. Pan X, Chen D, Xia Y, Wu X, Li T, Ou X, et al. Asymptomatic cases in a family cluster with SARS-CoV-2 infection. Lancet Infect Dis 2020;20:410-411. https://doi.org/10.1016/ S1473-3099(20)30114-6.

26. Lauer SA, Grantz KH, Bi Q, Jones FK, Zheng Q, Meredith HR, et al. The incubation period of coronavirus disease 2019 (COVID-19) from publicly reported confirmed cases: Estimation and application. Ann Intern Med 2020. [Epub ahead of print] 10 de marzo de 2020. https:// doi.org/10.7326/M20-0504.

27. Rasmussen SA, Smulian JC, Lednicky JA, Wen TS, Jamieson DJ. Coronavirus disease 2019 (COVID-19) and pregnancy: What obstetricians need to know. Am J Obstet Gynecol 2020. [Epub ahead of print] 24 de febrero de 2020. https://doi.org/10.1016/j.ajog.2020.02.017.

28. He F, Deng Y, Li W. Coronavirus disease 2019 (COVID-19): What we know? J Med Virol 20201-7. [Epub ahead of print] 14 de marzo de 2020. https://doi.org/10.1002/jmv.25766.

29. Ministerio de Sanidad. Informe técnico. Enfermedad por coronavirus, COVID-19. Valladolid, España: Junta de Castilla y León - Consejería de Sanidad; 2020. p. 26. Acceso 20 de marzo de 2020. Disponible en https://fundacionio. com/wp-content/uploads/2020/03/Informe_ Tecnico_COVID19-6-marzo-2020.pdf.

30. Li Q, Guan $X$, Wu P, Wang $X$, Zhou L, Tong $Y$, et al. Early transmission dynamics in Wuhan, China, of novel coronavirus-infected pneumonia. N Engl J Med 2020;382:1199-1207. https://doi.org/10.1056/NEJMoa2001316.

31. Wang Y, Wang Y, Chen $\mathbf{Y}$, Qin Q. Unique epidemiological and clinical features of the emerging 2019 novel coronavirus pneumonia (COVID-19) implicate special control measures. J Med Virol 2020. [Epub ahead of print] 5 de marzo de 2020. https://doi.org/10.1002/ jmv.25748.

32. World Health Organization (WHO). Report of the WHO-China Joint Mission on Coronavirus Disease 2019 (COVID-19) Ginebra, Suiza: 2020. p. 40. Actualizado para 16-24 febrero de 2020. Acceso 20 de marzo de 2020. Disponible en https://www.who.int/docs/default-source/co- 
ronaviruse/who-china-joint-mission-on-covid19-final-report.pdf.

33. Chen N, Zhou M, Dong $X$, Qu J, Gong F, Han $\mathbf{Y}$, et al. Epidemiological and clinical characteristics of 99 cases of 2019 novel coronavirus pneumonia in Wuhan, China: a descriptive study. Lancet 2020;395:507-513. https://doi. org/10.1016/S0140-6736(20)30211-7.

34. Chan KW, Wong VT, Tang SCW. COVID-19: An update on the epidemiological, clinical, preventive and therapeutic evidence and guidelines of integrative Chinese-Western medicine for the management of 2019 novel Coronavirus disease. Am J Chin Med 2020:1-26. [Epub ahead of print] 13 de marzo de 2020. https:// doi.org/10.1142/S0192415X20500378.

35. Pedersen SF, Ho Y-C. SARS-CoV-2: A storm is raging. J Clin Invest 2020; published online March 27, 2020. https://doi.org/10.1172/ JCl137647.

36. Battegay M, Kuehl R, Tschudin-Sutter S, Hirsch HH, Widmer AF, Neher RA. 2019-novel Coronavirus (2019-nCoV): estimating the case fatality rate - a word of caution. Swiss Med Wkly 2020;150:w20203. https://doi. org/10.4414/smw.2020.20203.

37. Baud D, Qi $X$, Nielsen-Saines K, Musso D, Pomar L, Favre G. Real estimates of mortality following COVID-19 infection. Lancet Infect Dis 2020. [Epub ahead of print] 12 de marzo de 2020. https://doi.org/10.1016/S14733099(20)30195-X.

38. Wang D, Hu B, Hu C, Zhu F, Liu X, Zhang J, et al. Clinical characteristics of 138 hospitalized patients with 2019 novel coronavirus-infected pneumonia in Wuhan, China. JAMA 2020. [Epub ahead of print] 7 de febrero de 2020. https://doi.org/10.1001/jama.2020.1585.

39. Zhou F, Yu T, Du R, Fan G, Liu Y, Liu Z, et al. Clinical course and risk factors for mortality of adult inpatients with COVID-19 in Wuhan, China: a retrospective cohort study. The Lancet 2020;395:1054-1062. https://doi.org/10.1016/ S0140-6736(20)30566-3.

40. Guan Wj, Ni Zy, Hu Y, Liang Wh, Ou Cq, He Jx, et al. Clinical characteristics of coronavirus disease 2019 in China. N Engl J Med 2020. [Epub ahead of print] 18 de febrero de 2020. https://doi.org/10.1056/NEJMoa2002032.
41. Chen H, Guo J, Wang $C$, Luo F, Yu X, Zhang

$\mathbf{W}$, et al. Clinical characteristics and intrauterine vertical transmission potential of COVID-19 infection in nine pregnant women: a retrospective review of medical records. The Lancet 2020;395:809-815. https://doi.org/10.1016/ S0140-6736(20)30360-3.

42. Zhou $P$, Yang $X L$, Wang $X G$, Hu B, Zhang $L$, Zhang $\mathbf{W}$, et al. A pneumonia outbreak associated with a new coronavirus of probable bat origin. Nature 2020;579:270-273. https://doi. org/10.1038/s41586-020-2012-7.

43. Inciardi RM, Lupi L, Zaccone G, Italia L, Raffo M, Tomasoni D, et al. Cardiac involvement in a patient with coronavirus disease 2019 (COVID-19). JAMA Cardiology 2020; published online March 27, 2020. https://doi.org/10.1001/ jamacardio.2020.1096.

44. Guo T, Fan $Y$, Chen $M$, Wu X, Zhang $L$, He T, et al. Cardiovascular implications of fatal outcomes of patients with coronavirus disease 2019 (COVID-19). JAMA Cardiology 2020; Published online March 27, 2020. https://doi. org/10.1001/jamacardio.2020.1017.

45. Jiang F, Deng L, Zhang L, Cai Y, Cheung CW, Xia Z. Review of the clinical characteristics of coronavirus disease 2019 (COVID-19). J Gen Intern Med 2020. [Epub ahead of print] 4 de marzo de 2020. https://doi.org/10.1007/s11606020-05762-w.

46. Chinese Centerfor Disease Control and Prevention, Novel Coronavirus Pneumonia Emergency Response Epidemiology Team. The epidemiological characteristics of an outbreak of 2019 novel coronavirus diseases (COVID-19) in China. Beijing: China CDC Weekly; 2020. p.10. Acceso 17 de abril de 2020. Disponible en http://weekly.chinacdc.cn/en/article/ id/e53946e2-c6c4-41e9-9a9b-fea8db1a8f51.

47. Huang $C$, Wang $Y$, Li $X$, Ren $L$, Zhao J, Hu $\mathbf{Y}$, et al. Clinical features of patients infected with 2019 novel coronavirus in Wuhan, China. Lancet 2020; 395:497-506. [Epub ahead of print] 15 de febrero de 2020. https://doi. org/10.1016/S0140-6736(20)30183-5.

48. Borges do Nascimento IJ, Cacic N, Abdulazeem HM, von Groote TC, Jayarajah U, Weerasekara I, et al. Novel coronavirus infection (COVID-19) in humans: A scoping review and 
meta-analysis. J Clin Med 2020;9:E941. https:// doi.org/10.3390/jcm9040941.

49. Cheung KS, Hung IFN, Chan PPY, Lung KC, Tso E, Liu R, et al. Gastrointestinal manifestations of SARS-CoV-2 infection and virus load in fecal samples from the hong kong cohort and systematic review and meta-analysis. Gastroenterology 2020. [Epub ahead of print] 03 de abril de 2020. https://doi.org/https://doi. org/10.1053/j.gastro.2020.03.065.

50. Lechien JR, Chiesa-Estomba CM, De Siati DR, Horoi M, Le Bon SD, Rodriguez A, et al. Olfactory and gustatory dysfunctions as a clinical presentation of mild-to-moderate forms of the coronavirus disease (COVID-19): a multicenter European study. Eur Arch Otorhinolaryngol 2020. [Epub ahead of print] 6 de abril de 2020. https://doi.org/10.1007/ s00405-020-05965-1.

51. Castro R, Luz PM, Wakimoto MD, Veloso VG, Grinsztejn B, Perazzo H. COVID-19: a metaanalysis of diagnostic test accuracy of commercial assays registered in Brazil. Braz J Infect Dis 2020. [Epub ahead of print] 18 de abril de 2020. https://doi.org/10.1016/j.bjid.2020.04.003.

52. Chen Z, Zhang Z, Zhai $X$, Li Y, Lin L, Zhao

$\mathbf{H}$, et al. Rapid and sensitive detection of anti-SARS-CoV-2 lgG using lanthanide-doped nanoparticles-based lateral flow immunoassay. Anal Chem 2020. [Epub ahead of print] 23 de abril de 2020. https://doi.org/10.1021/acs. analchem.0c00784.

53. World Health Organization (WHO). Advice on the use of point-of-care immunodiagnostic tests for COVID-19, Scientific Brief. Ginebra, Suiza: WHO; 2020. Acceso 16 de abril de 2020. Disponible en https://www.who.int/news-room/commentaries/detail/advice-on-the-use-of-point-ofcare-immunodiagnostic-tests-for-covid-19.

54. To KK-W, Tsang OT-Y, Leung W-S, Tam AR, Wu T-C, Lung DC, et al. Temporal profiles of viral load in posterior oropharyngeal saliva samples and serum antibody responses during infection by SARS-CoV-2: an observational cohort study. Lancet Infect Dis 2020; published online March 23, 2020. https://doi.org/10.1016/S14733099(20)30196-1.

55. Jin Y, Wang M, Zuo Z, Fan C, Ye F, Cai Z, et al. Diagnostic value and dynamic varian- ce of serum antibody in coronavirus disease 2019. Int J Infect Dis 2020; published online April 03, 2020. https://doi.org/10.1016/j. ijid.2020.03.065.

56. Wolfel R, Corman VM, Guggemos W, Seilmaier M, Zange S, Muller MA, et al. Virological assessment of hospitalized patients with $\mathrm{CO}$ VID-2019. Nature 2020. [Epub ahead of print] 1 de abril de 2020. https://doi.org/10.1038/ s41586-020-2196-x.

57. Zhao J, Yuan Q, Wang $H$, Liu W, Liao $X$, Su

$\mathbf{Y}$, et al. Antibody responses to SARS-CoV-2 in patients of novel coronavirus disease 2019. Clin Infect Dis 2020. [Epub ahead of print] 28 de marzo de 2020. https://doi.org/10.1093/ cid/ciaa344.

58. Food and Drug Administration (FDA). Emergency use authorizations. Silver Spring, MD: FDA; 2020. Acceso 16 de abril de 2020. Disponible en https://www.fda.gov/medical-devices/ emergency-situations-medical-devices/emergency-use-authorizations.

59. World Health Organization (WHO). Laboratory testing for 2019 novel coronavirus (2019$\mathrm{nCoV}$ ) in suspected human cases. Interim guidance. Ginebra, Suiza: WHO; 2020. p.10. Acceso 24 de marzo de 2020. Disponible en https://www.who.int/publications-detail/laboratory-testing-for-2019-novel-coronavirus-insuspected-human-cases-20200117.

60. Corman VM, Landt O, Kaiser M, Molenkamp R, Meijer A, Chu DKW, et al. Detection of 2019 novel coronavirus (2019-nCoV) by realtime RT-PCR. Euro Surveill 2020;25:2000045. https://doi.org/10.2807/1560-7917. ES.2020.25.3.2000045.

61. Nitkin K. Coronavirus screening test developed at Johns Hopkins. Baltimore, USA: Johns Hopkins Medicine; 2020. Acceso 30 de marzo de 2020. Disponible en https://www.hopkinsmedicine.org/coronavirus/screening-test.html.

62. He $X$, Lau EH, Wu P, Deng $X$, Wang J, Hao $\mathbf{X}$, et al. Temporal dynamics in viral shedding and transmissibility of COVID-19. medRxiv 2020:2020.2003.2015.20036707. https://doi. org/10.1101/2020.03.15.20036707.

63. Kim JY, Ko JH, Kim Y, Kim YJ, Kim JM, Chung YS, et al. Viral load kinetics of SARS-CoV-2 infection in first two patients in Korea. J Korean 
Med Sci 2020;35:e86. https://doi.org/10.3346/ jkms.2020.35.e86.

64. Xiao AT, Tong YX, Zhang S. False-negative of RT-PCR and prolonged nucleic acid conversion in COVID-19: Rather than recurrence. J Med Virol 2020. [Epub ahead of print] 9 de abril de 2020. https://doi.org/10.1002/ jmv.25855.

65. Lan L, Xu D, Ye G, Xia C, Wang S, Li Y, et al. Positive RT-PCR test results in patients recovered from COVID-19. JAMA 2020. [Epub ahead of print] 27 de febrero de 2020. https://doi. org/10.1001/jama.2020.2783.

66. Xing Y, Mo P, Xiao Y, Zhao O, Zhang Y, Wang F. Post-discharge surveillance and positive virus detection in two medical staff recovered from coronavirus disease 2019 (COVID-19), China, January to February 2020. Euro Surveill 2020;25. https://doi.org/10.2807/1560-7917. ES.2020.25.10.2000191.

67. Zou L, Ruan F, Huang M, Liang L, Huang $H$, Hong Z, et al. SARS-CoV-2 viral load in upper respiratory specimens of infected patients. N Engl J Med 2020;382:1177-1179. https://doi. org/10.1056/NEJMc2001737.

68. Vogels CBF, Brito AF, Wyllie AL, Fauver JR, Ott IM, Kalinich CC, et al. Analytical sensitivity and efficiency comparisons of SARS-COV-2 qRT-PCR assays. medRxiv 2020:2020.2003.2030.20048108. https://doi. org/10.1101/2020.03.30.20048108.

69. Saavedra-Trujillo $\mathbf{C H}$. Consenso colombiano de atención, diagnóstico y manejo de la infección por SARS-COV-2/COVID 19 en establecimientos de atención de la salud. Recomendaciones basadas en consenso de expertos e informadas en la evidencia. Infectio 2020;24(S1):p.163. https://doi.org/http:// dx.doi.org/10.22354/in.v24i3.851.

70. Guo L, Ren L, Yang S, Xiao M, Chang D, Yang F, et al. Profiling early humoral response to diagnose novel coronavirus disease (COVID-19). Clin Infect Dis 2020; published online 21 March 2020. https://doi.org/10.1093/cid/ciaa310.

71. Li LQ, Huang $T$, Wang YQ, Wang ZP, Liang $Y$, Huang TB, et al. 2019 novel coronavirus patients' clinical characteristics, discharge rate, and fatality rate of meta-analysis. J Med Virol
2020. [Epub ahead of print] 12 de marzo de 2020. https://doi.org/10.1002/jmv.25757.

72. Centers for Disease Control and Prevention (CDC). Information for clinicians on investigational therapeutics for patients with COVID-19. Atlanta, USA: CDC; 2020. Acceso 16 de abril de 2020. Disponible en https://www.cdc.gov/ coronavirus/2019-ncov/hcp/therapeutic-options.html.

73. Ford N, Vitoria M, Rangaraj A, Norris SL, Calmy A, Doherty M. Systematic review of the efficacy and safety of antiretroviral drugs against SARS, MERS or COVID-19: initial assessment. J Int AIDS Soc 2020;23:e25489. https://doi. org/10.1002/jia2.25489.

74. Martinez MA. Compounds with therapeutic potential against novel respiratory 2019 coronavirus. Antimicrob Agents Chemother 2020. [Epub ahead of print] 9 de marzo de 2020. https://doi.org/10.1128/AAC.00399-20.

75. Lythgoe MP, Middleton P. Ongoing clinical trials for the management of the COVID-19 pandemic. Trends Pharmacol Sci 2020. [Epub ahead of print] 9 de abril de 2020. https://doi. org/10.1016/j.tips.2020.03.006.

76. Touret $F$, de Lamballerie $X$. Of chloroquine and COVID-19. Antiviral Res 2020;177:104762. https://doi.org/10.1016/j. antiviral.2020.104762.

77. Richardson P, Griffin I, Tucker C, Smith D, Oechsle O, Phelan A, et al. Baricitinib as potential treatment for 2019-nCoV acute respiratory disease. Lancet 2020;395:e30-e31. https:// doi.org/10.1016/S0140-6736(20)30304-4.

78. Ye M, Fu D, Ren Y, Wang F, Wang D, Zhang F, et al. Treatment with convalescent plasma for COVID-19 patients in Wuhan, China. J Med Virol 2020. [Epub ahead of print] 15 de abril de 2020. https://doi.org/10.1002/jmv.25882.

79. Pearce K. Antibodies from COVID-19 survivors could be used to treat patients, protect those at risk. Baltimore, USA: The Hub, Johns Hopkins University; 2020. Acceso 30 de marzo de 2020. Disponible en https://hub.jhu.edu/2020/03/13/ covid-19-antibody-sera-arturo-casadevall/.

80. Tiberghien $\mathbf{P}$, de Lambalerie $X$, Morel $\mathbf{P}, \mathbf{G a -}$ Ilian $\mathbf{P}$, Lacombe $\mathbf{K}$, Yazdanpanah $\mathbf{Y}$. Collecting and evaluating convalescent plasma for 
COVID-19 treatment: why and how. Vox Sang 2020. [Epub ahead of print] 2 de abril de 2020. https://doi.org/10.1111/vox.12926.

81. World Health Organization (WHO). WHO R\&D Blueprint: informal consultation on prioritization of candidate therapeutic agents for use in novel coronavirus 2019 infection, Geneva, Switzerland, 24 January 2020. Ginebra, Suiza: World Health Organization; 2020. p.16. Acceso 18 de marzo de 2020. Disponible en https://extranet.who.int/iris/restricted/handle/10665/330680.

82. Food and Drug Administration (FDA). Donate COVID-19 Plasma. Silver Spring, MD: FDA; 2020. Acceso 16 de abril de 2020. Disponible en https://www.fda.gov/emergency-preparedness-and-response/coronavirus-disease2019-covid-19/donate-covid-19-plasma.

83. Food and Drug Administration (FDA). Recommendations for investigational COVID-19 convalescent plasma. Silver Spring, MD: FDA; 2020. Acceso 16 de abril de 2020. Disponible en https://www.fda.gov/vaccinesblood-biologics/investigational-new-drug- ind-or-device-exemption-ide-process-cber/ recommendations-investigational-covid19-convalescent-plasma.

84. Food and Drug Administration (FDA). Coronavirus (COVID-19) update: FDA encourages recovered patients to donate plasma for development of blood-related therapies. Silver Spring, MD: FDA; 2020. Acceso 16 de abril de 2020. Disponible en https://www.fda.gov/news-events/ press-announcements/coronavirus-covid-19-update-fda-encourages-recovered-patients-donate-plasma-development-blood.

85. European Blood Alliance (EBA). Convalescent plasma (CCP). Amsterdam, Holanda: EBA; 2020. Acceso 16 de abril de 2020. Disponible en https://europeanbloodalliance.eu/activities/convalescent-plasma-cpp/.

86. World Health Organization (WHO). DRAFT landscape of COVID-19 candidate vaccines-20 April 2020. Ginebra, Suiza: WHO; 2020. p. 4. Acceso 20 de abril de 2020. Disponible en https://www.who.int/blueprint/priority-diseases/key-action/novel-coronavirus-landscapencov.pdf?ua=1. 

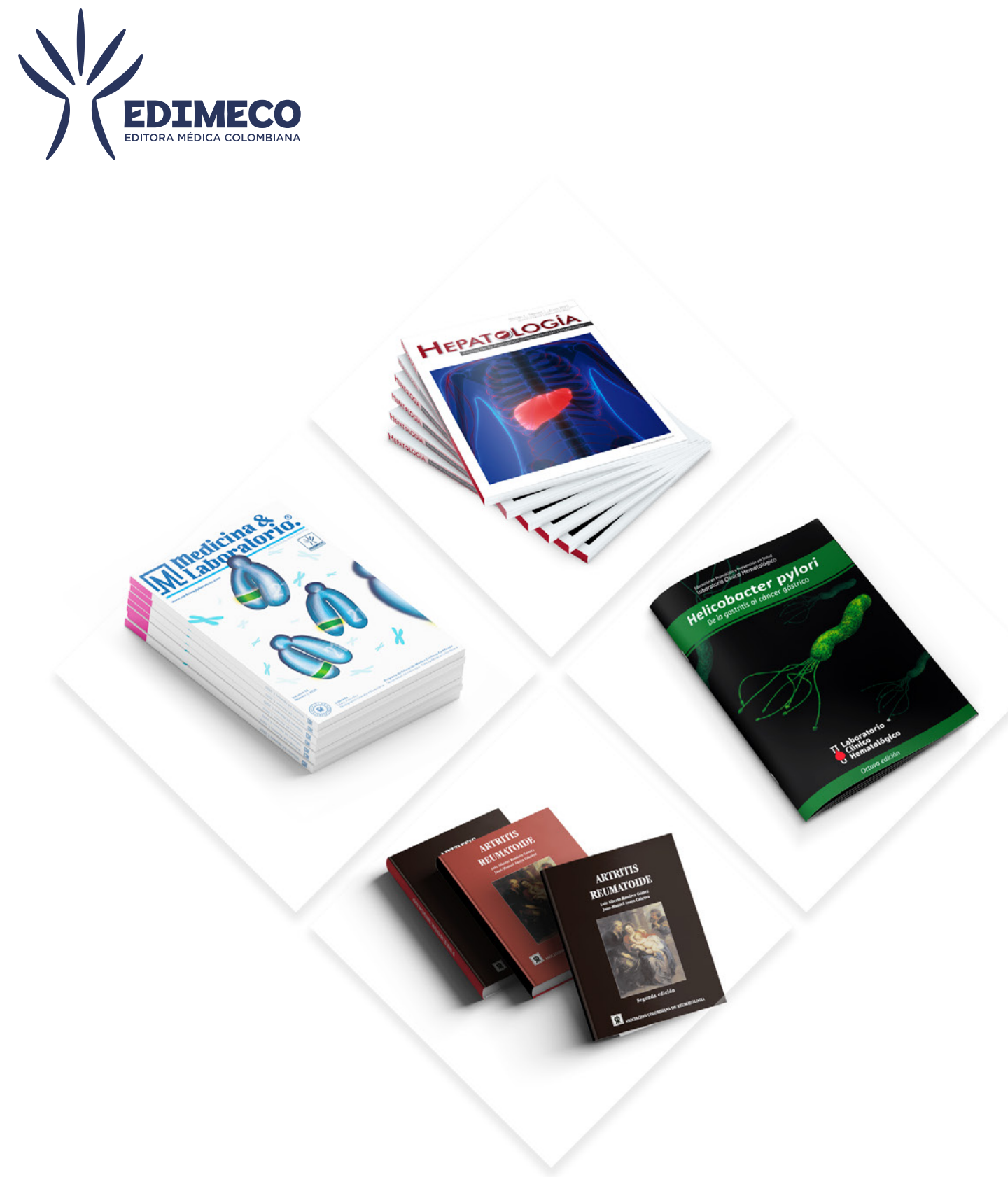

\section{SOMOS UN UNIVERSO DE POSIBILIDADES}

Tenemos el equipo indicado para brindarte la mejor solución.

Libros, revistas, folletos, manuales, boletines y plegables para el área de las ciencias médicas, aportando a las comunidades académicas, científicas y profesionales un valor agregado.

Déjanos conocer tu idea, contáctanos. 